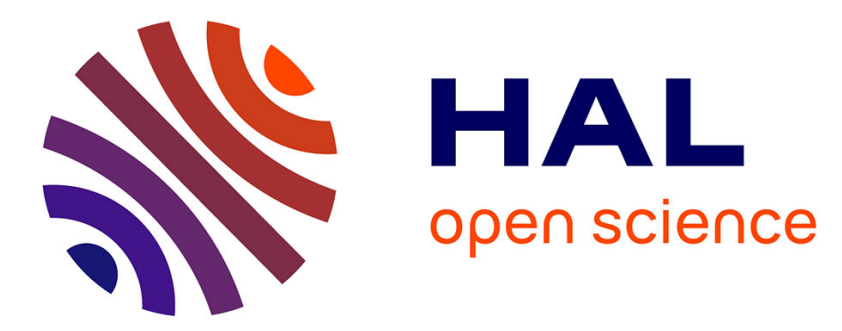

\title{
Formulation of rifampicin-cyclodextrin complexes for lung nebulization
}

Frederic Tewes, Julien Brillault, William Couet, Jean-Christophe Olivier

\section{To cite this version:}

Frederic Tewes, Julien Brillault, William Couet, Jean-Christophe Olivier. Formulation of rifampicincyclodextrin complexes for lung nebulization. Journal of Controlled Release, 2008, 129, pp.93 - 99. 10.1016/j.jconrel.2008.04.007 . inserm-01102812

\section{HAL Id: inserm-01102812 https://www.hal.inserm.fr/inserm-01102812}

Submitted on 13 Jan 2015

HAL is a multi-disciplinary open access archive for the deposit and dissemination of scientific research documents, whether they are published or not. The documents may come from teaching and research institutions in France or abroad, or from public or private research centers.
L'archive ouverte pluridisciplinaire HAL, est destinée au dépôt et à la diffusion de documents scientifiques de niveau recherche, publiés ou non, émanant des établissements d'enseignement et de recherche français ou étrangers, des laboratoires publics ou privés. 


\section{Formulation of Rifampicin - cyclodextrin complexes}

\section{for lung nebulization}

Frédéric Tewes $^{1,2, *}$, Julien Brillault ${ }^{1,2}$, William Couet ${ }^{1,2}$, Jean-Christophe Olivier ${ }^{1,2}$.

${ }^{1}$ Inserm ERI-23, 40 avenue du recteur Pineau, 86022 Poitiers, France

${ }^{2}$ Université de Poitiers, UFR Médecine-Pharmacie, 6 rue de la Milétrie, 86021 Poitiers,

France

Tel.: +335 494549 29; fax: +335 494543 78. E-mail: ftewes@univ-poitiers.fr

Keywords: cyclodextrin, permeability, lung, Calu-3, rifampicin 


\section{Abstract}

Lung administrations of antibiotics by nebulization are promising for improving treatment efficiency against pulmonary infections, as they increase drug concentration at sites of infection while minimizing systemic side effects. For low soluble molecules like rifampicin, cyclodextrins (CD) may improve lung delivery by permitting higher dosing. For this purpose, we investigated rifampicin-CD complexes in terms of rifampicin apparent solubility enhancement, effect on in vitro permeability on a Calu-3 broncho-alveolar model and of in vitro antibacterial activity against Acinetobacter baumannii. Complexation efficiency between rifampicin and hydroxypropyl- $\beta$-Cyclodextrin $(\mathrm{HP} \beta \mathrm{CD})$ or methylated $\beta$-cyclodextrin (RAMEB) was pH-dependent, involving the piperazin group. Rifampicin phase solubility diagrams constructed at $\mathrm{pH} 9$ showed an $\mathrm{A}_{\mathrm{L}}$-type curve for RAMEB and a $\mathrm{B}_{\mathrm{S}}$-type for HP $\beta C D$. Stability constants calculated for a 1:1 molar ratio of $\mathrm{CD} /$ rifampicin were $73.4 \pm$ 8.2 $\mathrm{M}^{-1}$ for RAMEB and $68.5 \pm 5.2 \mathrm{M}^{-1}$ for HP $\beta C D$. Complexes with HP $\beta C D$ or RAMEB increased 7.6 times and 22 times respectively the apparent solubility of rifampicin and were found to be satisfactorily stable for 2 days when diluted in a solution at physiological $\mathrm{pH}$. Activity of RAMEB and HP $\beta$ CD complexes measured by the total rifampicin MIC against $A$. baumannii was similar or lower to free rifampicin MIC respectively. Complexation did not alter the rifampicin permeability in the timescale of 1 hour as evaluated with a Calu-3 epithelial cell model, but acted as a reservoir for rifampicin. In conclusion, this work reports that CDs can be used as vectors for pulmonary nebulization to increase the amount of active rifampicin and optimize its lung pharmacokinetic profile. 


\section{Introduction}

Antibiotic overuse and misuse have led to the positive selection of bacteria which are resistant to most antibiotics. These multidrug-resistant (MDR) bacteria, mainly isolated in hospital units, are responsible for nosocomial infections that represent a physician's challenge throughout the world. Recently, Acinetobacter baumannii, responsible for hospital-acquired pneumonia, has emerged as one of the most ubiquitous antibiotic-resistant gram-negative nosocomial pathogens among critically ill patients [1-3]. Although typically used carbapenems, ampicillin-sulbactam, and amikacin have retained excellent in vitro and clinical activities against susceptible strains of $A$. baumannii, a growing number of reports indicates resistance to these antibacterials [4-8]. This gives rise to uncertainty about which antimicrobials should be chosen for treatment, resulting in increased patient mortality [9].

As a result, older antibiotics, including colistin and rifampicin (Fig. 1) are administered by intravenous route to treat patients infected with MDR A. baumannii [4, 9-11]. However, pulmonary infections do not always respond well to such systemic therapy, due to insufficient drug diffusion into pulmonary tissue and lumen $[12,13]$. Bacteria that have persisted over treatment may develop resistance, but higher drug doses to compensate for poor diffusion may lead to systemic toxicity. Furthermore systemic antibiotic administration may not be justified for A. baumannii nosocomial pneumonia as these infections are generally limited to the pulmonary area. Additionally, most patients find difficult to adhere to treatments that necessitate several administrations a day to maintain efficient antibiotics concentration. Therefore, it is imperative to develop new ways to deliver and use antibiotics to avoid the selection and spread of resistant A. baumannii and to improve patients' compliance by decreasing dosing frequency. 
Antibiotic delivery systems administered as aerosols via the pulmonary route aim to deliver high drug concentrations directly at the site of infection while minimizing systemic biodistribution and toxicity. Rifampicin is a so-called concentration-dependent antibiotic [14]. The rate and extent of bacterial kill is related to the attainment of sufficiently high maximum concentration (Cmax) relative to the minimal inhibitory concentration (MIC). Higher its concentration in targeted sites higher its bactericide activity. However, rifampicin has a rather low aqueous solubility (from 1.58 to $3.35 \mathrm{mg} / \mathrm{mL}$ at $\mathrm{pH} 7.4[15,16]$ ), limiting the possibility of achieving high concentration in the broncho-alveolar epithelium-lining fluid (ELF) when administered as aerosolized solution.

One way to enhance rifampicin (apparent) solubility is the use of cyclodextrins (CDs), as complexing and solubilizing agent. Cyclodextrins enhance aqueous apparent solubility due to the formation of water-soluble inclusion complexes in which apolar interior of the hollow, truncated cone-like CD structure encapsulates hydrophobic parts of drug molecules. CDs have already been proposed for lung administration [17]. Aqueous solutions of CD derivatives (hydroxypropyl- $\beta$-cyclodextrin (HP $\beta C D$ ) and randomly methylated $\beta$-cyclodextrin (RAMEB) could be aerosolized with nebulizers commonly used in clinical practice, resulting in droplet size range compatible with pulmonary deposition. Additionally, the short-term exposure to inhaled HP $\beta C D$ and RAMEB solutions was found to be non-toxic [18].

The purpose of the present work was to study the complexation behavior of rifampicin with $\mathrm{HP} \beta \mathrm{CD}$ or RAMEB in order to optimize the formulation of inclusion complexes and to demonstrate their usefulness in terms of rifampicin solubility enhancement. Then lung transport of rifampicin as complex with cyclodextrins was evaluated in an in vitro Calu-3 broncho-alveolar epithelial cell model [19]. Finally the antibacterial activity was assessed in vitro against $A$. Baumannii. 


\section{Materials and Methods}

\section{Materials}

Rifampicin ( $\geq 97.0 \%$ (HPLC)) and fluorescein (sodium salt) were purchased from SigmaAldrich. 2-hydroxypropyl- $\beta$-cyclodextrin (HP $\beta C D)$ with a degree of substitution per glucose unit of $0.6-0.9$ and a MW of $1510 \mathrm{~g} / \mathrm{mol}$ (Kleptose ${ }^{\circledR} \mathrm{HP}$ ) was obtained from Roquette. Cavasol $^{\circledR}$ W7 M pharma, a randomly methylated $\beta$-cyclodextrin derivative (RAMEB) with a degree of substitution per glucose unit of 1.6 and with a MW of $1310 \mathrm{~g} / \mathrm{mol}$ was obtained from Wacker. Cell culture media and supplements were from Hyclone. Phosphate buffered saline (PBS) tablets and all other chemicals of reagent grade were purchased from SigmaAldrich. Ultrapure water was produced by a Direct- $\mathrm{Q}^{\mathrm{TM}}$ water purification system (Millipore).

\section{Rifampicin - CD complexation studies}

Preliminary experiments were carried out in order to determine the optimal $\mathrm{pH}$ for the formation of complexes. An excess amount of rifampicin (until saturation) was added to $1 \mathrm{~mL}$ of $5 \% \mathrm{w} / \mathrm{v}$ of $\mathrm{CD}(0.033 \mathrm{M}$ of HP $\beta \mathrm{CD}-0.038 \mathrm{M}$ RAMEB) solutions buffered either at $\mathrm{pH} 4$ with $0.05 \mathrm{M}$ of citric acid/ sodium citrate, $\mathrm{pH} 7.4$ with $0.05 \mathrm{M}$ of $\mathrm{PBS}$ or $\mathrm{pH} 9$ with $0.05 \mathrm{M}$ of sodium tetraborate. Suspensions were stirred in a $37^{\circ} \mathrm{C}$ water bath for 7 days in order to reach equilibrium. Samples were filtered through a $0.2 \mu \mathrm{m}$ syringe filter (Acrodisc ${ }^{\circledR}$ ). The first $500 \mu \mathrm{L}$ was discarded to avoid unspecific rifampicin membrane filter adsorption and the total rifampicin concentration was assayed in the remaining volume by HPLC. Each experiment was carried out in triplicate. Phase solubility diagrams were performed similarly by using various cyclodextrin concentration solutions buffered at $\mathrm{pH}$ 9. Total cyclodextrin concentration ranges were $0,2.5,5,10,15$ and $30 \% \mathrm{w} / \mathrm{v}(0-0.23 \mathrm{M}$ of RAMEB and $0-$ $0.20 \mathrm{M}$ of $\mathrm{HP} \beta \mathrm{CD})$. 


\section{Constants calculations}

In the hypothesis that cyclodextrin-rifampicin complexes (CD-RIF) were of 1:1 stoichiometry, the apparent stability constant Ks was calculated using the following equation:

$$
\mathrm{Ks}=\frac{[\mathrm{CD}-\mathrm{RIF}]}{[\mathrm{RIF}]_{\text {free }} \cdot[C D]_{\text {free }}} \quad C D+\mathrm{RIF} \stackrel{\mathrm{Ks}}{\longleftrightarrow} \mathrm{CD}-\mathrm{RIF} \quad \text { Equation } 1
$$

where $[\mathrm{CD}-\mathrm{RIF}],[\mathrm{RIF}]$ free and $[\mathrm{CD}]_{\text {free }}$ are the concentrations of the CD-RIF complex, free rifampicin and free cyclodextrin respectively.

In excess of rifampicin, $[R I F]_{\text {free }}$ can be considered as equal to rifampicin solubility $\mathrm{S}_{0}$ and the equation becomes:

$$
\mathrm{Ks}=\frac{[\mathrm{CD}-\mathrm{RIF}]}{\mathrm{S}_{0} \cdot[C D]_{\text {free }}}
$$

Equation 2

Thus Ks was calculated as defined in equation 3, using the slope of the linear regression obtained from the phase diagram representing the total rifampicin molar concentration $\left([\mathrm{RIF}]_{\text {free }}+[\mathrm{CD}-\mathrm{RIF}]\right)$ versus the total CD molar concentration.

$$
\mathrm{Ks}=\frac{\text { slope }}{\mathrm{S}_{0}(1-\text { slope })}
$$

Equation 3

The complexation efficiency (CE), corresponding to the complex to free cyclodextrin concentration ratio, was calculated from the phase diagram slope according to equation 4 [20].

$$
C E=\frac{[C D-\text { Rif }]}{[C D]_{\text {free }}}=\frac{\text { slope }}{1-\text { slope }}
$$




\section{Complex stability studies.}

Solutions of complex formed with rifampicin $(59 \mathrm{mM})$ and RAMEB $(0.23 \mathrm{M})$ in $0.05 \mathrm{M}$ of sodium tetraborate ( $\mathrm{pH}$ 9) were diluted 6 times in Ringer-HEPES medium ( $\mathrm{pH} 7.4$ ) or in 0.1 $\mathrm{M}$ of citric acid/ citrate buffer ( $\mathrm{pH}$ 4). These dilutions did not modify the initial $\mathrm{pH}$ of buffers. After $1 \mathrm{H}$ or 2 days of stirring, solutions were filtered on $0.2 \mu \mathrm{m}$ filter before rifampicin assay.

\section{Calu-3 cell culture and rifampicin transepithelial transport experiments}

Calu-3 cells were obtained from the American Type Culture Collection and used between passages 22 and 30. The cells were cultured in DMEM/Ham's F12 (1/1) supplemented with L-glutamine (2 mM; final concentration), fetal calf serum $(10 \% \mathrm{v} / \mathrm{v}$; final concentration) and gentamycin $(50 \mu \mathrm{g} / \mathrm{mL}$; final concentration). Cell monolayer were obtained by seeding cells

$\left(5 \times 10^{5}\right.$ cells $\left./ \mathrm{cm}^{2}\right)$ onto tissue culture inserts (Nunc polycarbonate filters, with a $4.2 \mathrm{~cm}^{2}$ growth surface area) placed in six-well plates and maintained at $37^{\circ} \mathrm{C}$ in a humidified atmosphere of $5 \% \mathrm{v} / \mathrm{v} \mathrm{CO}$ in air. Growth medium, $1 \mathrm{~mL}$ in the donor (upper) compartment and $1 \mathrm{~mL}$ in the acceptor (lower) compartment, was replaced with fresh medium every other day. The epithelial monolayer confluence was estimated by visual inspection under photonic microscope and was generally achieved 8 days after seeding. Tight junction integrity was verified for each insert by fluorescein permeability assay performed concomitantly with rifampicin transport experiments (see below).

Transport experiments were carried out in Ringer-HEPES solution $(150 \mathrm{mM} \mathrm{NaCl}, 5.2 \mathrm{mM}$ $\mathrm{KCl}, 2.2 \mathrm{mM} \mathrm{CaCl}_{2}, 0.2 \mathrm{mM} \mathrm{MgCl}_{2}-6 \mathrm{H}_{2} \mathrm{O}, 6 \mathrm{mM} \mathrm{NaHCO}_{3}, 5 \mathrm{mM}$ HEPES, 2.8mM Glucose, $\mathrm{pH}=7.4$ ). Inserts containing cell monolayer at confluence were first equilibrated with RingerHEPES solution ( $1 \mathrm{~mL}$ in each compartment) for $15 \mathrm{~min}$. The medium was then discarded and the inserts were transferred into six-well plates containing $1 \mathrm{~mL}$ of Ringer-HEPES 
solution per well (acceptor compartment). Then $400 \mu \mathrm{L}$ of the test solutions supplemented with fluorescein $(10 \mu \mathrm{g} / \mathrm{mL}$; final concentration) used as the tight junction integrity marker was added to the donor compartment and cells were incubated at $37^{\circ} \mathrm{C}$. After $60 \mathrm{~min}, 500 \mu \mathrm{L}$ samples were collected from the acceptor compartments for rifampicin and fluorescein assay by HPLC.

For rifampicin transport experiments rifampicin (rifampicin concentrations range: $0.34-$ $2.5 \mathrm{mM}$ ) was dissolved in the Ringer-HEPES solution. For transport experiments performed with cyclodextrin-rifampicin complexes, the borate-buffered rifampicin-cyclodextrin solutions ( $\mathrm{pH}$ 9) were buffered at $\mathrm{pH} 7.4$ by dilution in a modified Ringer HEPES solution $\mathrm{pH}$ 7.4 (i.e. $100 \mathrm{mM}$ HEPES, $\mathrm{pH} 7.4$, and $\mathrm{NaCl}$ concentration adjusted to obtain a $290 \mathrm{mOsm} / \mathrm{kg}$ osmolarity). Total rifampicin concentration ranged from 1.25 to $22 \mathrm{mM}$. In all cases, samples contained fluorescein (10 $\mu \mathrm{g} / \mathrm{mL}$ final concentrations) to check for the tight junction integrity. Three inserts were used for each condition. In all cases, the amount of rifampicin transferred from the donor to the acceptor compartments never exceeded $5 \%$ of the input.

Fluxes $J_{a-b}$ in the apical-to-basal direction were calculated as follows:

$$
J_{a-b}=\left(C_{a} \cdot V_{a}\right) /(S . t)
$$

\section{Equation 5}

where $C_{a}$ is the concentration in rifampicin and $V_{a}$ the volume $(1 \mathrm{~mL})$ of solution in the acceptor compartment, $t$ the incubation time $(60 \mathrm{~min})$ and $S$ the insert surface area $\left(4.2 \mathrm{~cm}^{2}\right)$. The total, i.e. filter-plus-cell, permeability coefficients $\left(P_{\text {Total }}\right)$ for both rifampicin and fluorescein in the apical-to-basal direction were calculated using the following equation:

$$
P_{\text {Total }}=J_{a-b} / C_{d}
$$

where $C_{d}$ is the initial concentration in the donor compartment. 
$P_{\text {Total }}$ is the resultant of epithelial cell barrier permeability $P_{e}$ and filter permeability $P_{f}$. For diffusion through membranes in series, the mathematical relationship between permeability coefficients is: $1 / P_{\text {Total }}=1 / P_{e}+1 / P_{f}$ [21]. Therefore $P_{e}$ can be calculated from the formula: $1 / P_{e}=1 / P_{\text {Total }}-1 / P_{f}$. However, due to high values of fluorescein and rifampicin $P_{f}(131 \pm 12$ x $10^{-6}$ and $139 \pm 14 \times 10^{-6} \mathrm{~cm} / \mathrm{s}$ respectively) compared to $P_{\text {Total }}, 1 / P_{f}$ was neglected and $P_{e}=$ $P_{\text {total }}$. Mean $P_{e}$ value for $10 \mu \mathrm{g} / \mathrm{mL}$ fluorescein $(\mathrm{n}=6)$ was calculated to be $0.57 \pm 0.06 \times 10^{-6}$ $\mathrm{cm} / \mathrm{s}$ with extremes of $0.40-0.70 \times 10^{-6} \mathrm{~cm} / \mathrm{s}$. The threshold $P_{e}$ value of $0.7 \times 10^{-6} \mathrm{~cm} / \mathrm{s}$ for fluorescein was retained for the tight junction integrity rejection parameter.

\section{Determination of minimum inhibitory concentration (MIC) of rifampicin}

MIC of rifampicin, free or after complexation with $\mathrm{CD}$, was determined by a serial two-fold dilution method using Mueller-Hinton medium. Reference strain A. baumannii CIP7010 (Institut Pasteur Strain Collection, Paris, France) was used at a concentration of $5.10^{7} \mathrm{CFU} / \mathrm{mL}$ and incubated in the presence of rifampicin for $18 \mathrm{~h}$ at $37^{\circ} \mathrm{C}$. The total rifampicin concentrations ranged from 1 to $70 \mathrm{mg} / \mathrm{L}\left(1.21 \times 10^{-3}-85 \times 10^{-3} \mathrm{mM}\right)$. The bacteria growth was evaluated visually (clear or cloudy media).

\section{Rifampicin and fluorescein assay}

Stock standard solution of rifampicin $(2.8 \mathrm{mg} / \mathrm{mL}-3 \mathrm{mM})$ was prepared by dissolving $28 \mathrm{mg}$ of rifampicin in $10 \mathrm{ml}$ acetonitrile and was stored protected from light at $-20^{\circ} \mathrm{C}$. Stock standard solution of fluorescein $(1 \mathrm{~g} / \mathrm{L})$ was prepared by dissolving $10 \mathrm{mg}$ of fluorescein in 10 $\mathrm{ml}$ Ringer-HEPES and was stored protected from light at $4{ }^{\circ} \mathrm{C}$. Rifampicin calibration standards $\left(1-140 \mu \mathrm{g} / \mathrm{mL} ; 1.21 \times 10^{-3}-170 \times 10^{-3} \mathrm{mM}\right)$ were prepared on the days of assays by diluting the stock solutions with water (for CD complexation assays), or with Ringer

solution supplemented with EDTA (0.2 g/L final concentration) and with standard fluorescein 
(0.3 to $0.01 \mathrm{mg} / \mathrm{L}$ concentrations) (for in vitro diffusion studies and simultaneous determination of rifampicin and fluorescein concentrations). Standards and samples were analyzed by HPLC with the following method. Samples containing Ringer were all supplemented with EDTA (0.2 g/L final concentration). Twenty $\mu \mathrm{L}$ were injected in the chromatograph with Waters 717 plus autosampler. The mobile phase consisted of $0.05 \mathrm{M}$ of $\mathrm{KH}_{2} \mathrm{PO}_{4}$ aqueous solution ( $\left.\mathrm{pH} 4.5\right)$, and acetonitrile in 67:33 (v/v) ratio, and was run at a flow-rate of $1 \mathrm{~mL} / \mathrm{min}$. Separation was achieved with a Kromasil ${ }^{\circledR}$ C18 reversed-phase column $(250 \mathrm{~mm}$ length $\times 3 \mathrm{~mm}$ i.d., $5 \mu \mathrm{m}$ particle size $)$ thermostated at $30^{\circ} \mathrm{C}$. The eluate was monitored for 15 minutes at $333 \mathrm{~nm}$ with a Jasco UV-1570 detector for rifampicin determination, and, when applicable, with a Jasco FP-920 fluorescence detector mounted in series for fluorescein determination (excitation wavelength: $490 \mathrm{~nm}$; detection wavelength: $530 \mathrm{~nm}$ ). Signals were integrated with EZchrom Elite 3.1 software. Retention times were 9 and 11 minutes for rifampicin and fluorescein respectively. Means of coefficient of determination $\left(r^{2}\right)$ of the linear regression equations performed on five concentration series of fluorescein or rifampicin, built at various days, were greater than 0.999 . 


\section{Results - Discussions}

\section{Complexation studies}

Rifampicin molecule (Fig.1) contains several ionizable groups leading to the formation of various ionic species as a function of $\mathrm{pH}$. The two main ionizable groups between $\mathrm{pH} 1$ and 11 are the hydroxyl in $\mathrm{C} 4$ and the 3 '-piperazin nitrogen, with pKa of 1.7 and 7.9 respectively [22]. In order to evaluate the effect of rifampicin ionized groups on the formation of complexes with cyclodextrins, apparent rifampicin solubility values were determined at $\mathrm{pH} 4$, 7.4 and 9 in the presence of $5 \% \mathrm{w} / \mathrm{v}$ of HP $\beta C D$ or RAMEB and compared to solubility of rifampicin alone. As shown on Fig. 2A, the rifampicin solubility was the lowest at $\mathrm{pH} 4$ and increased with $\mathrm{pH}$, as already described by Agrawal et al. [16]. This increase was of low magnitude between $\mathrm{pH} 4$ and $\mathrm{pH} 7.4$ (2-time increase) and higher from $\mathrm{pH} 7.4$ to 9 (further 3.6-time increase). The increase in rifampicin solubility with $\mathrm{pH}$ may be related to the change in rifampicin ionization states. Indeed, three ionic species can be expected in the $\mathrm{pH}$ range 111; a cationic form predominating at $\mathrm{pH}<1.7$, a globally neutral zwitterionic form between pH 1.7 and pH 7.9 and an anionic form above 7.9 (Fig. 2B). The lower solubility observed at $\mathrm{pH} 4$ was attributed to predominant intra/intermolecular charge neutralization of zwitterions at the expense of interactions with water molecules. From pH 6 to 9 , zwitterions are replaced by anionic rifampicin possessing higher solubility. In the presence of cyclodextrins, rifampicin apparent solubility also varied as a function of the $\mathrm{pH}$ (Fig. 2A). At $\mathrm{pH} 4,5 \% \mathrm{w} / \mathrm{v} \mathrm{HP} \beta \mathrm{CD}$ or RAMEB concentration had no effect on rifampicin apparent solubility, demonstrating an ineffective complexation. At $\mathrm{pH} 7.4$, with $5 \% \mathrm{w} / \mathrm{v}$ of RAMEB, rifampicin apparent solubility was two times higher than rifampicin solubility, whereas $\mathrm{HP} \beta C D$ at similar concentration had no effect. At $\mathrm{pH} 9,5 \%$ of $\mathrm{HP} \beta \mathrm{CD}$ or RAMEB noticeably increased rifampicin apparent solubility. As proposed by Rao et $a l$. [23] from I.R. spectroscopic measurements, rifampicin - 
$\mathrm{CD}$ interaction is mediated through the piperazin group. Increase in $\mathrm{pH}$ from 7.4 to 9 led to the deprotonation of the N-3' of the piperazin group (pKa 7.9) and favoured higher interaction between this group and the apolar interior of $\mathrm{CD}$, as showed by the increase in rifampicin apparent solubility.

Shown to be favorable to the formation of rifampicin $\mathrm{CD}$ complexes, $\mathrm{pH} 9$ was chosen to perform phase solubility diagrams (Fig 3). In the 0 to $0.23 \mathrm{M}$ RAMEB concentration range, the rifampicin apparent solubility increased linearly and corresponded to an $\mathrm{A}_{\mathrm{L}}$ type curve, suggesting the formation of $1 / X(X \geq 1)$ stoichiometry RAMEB/rifampicin complex [24]. As suggested above, the rifampicin piperazin group is internalized in CD. Due to the size of this group, only one piperazin group is likely to be included in the $\beta C D$ hydrophobic cavity and the hypothesis of $1 / 1$ complex between RAMEB and rifampicin was made. For HP $\beta C D$, the phase solubility diagram constructed in the 0 to $0.20 \mathrm{M}$ concentration range corresponded to a $\mathrm{B}_{\mathrm{S}}$-type curve: rifampicin apparent solubility increased linearly with HP $\beta C D$ concentration in the range of $0-0.066 \mathrm{M}$, then plateaued. Consequently, the hypothesis of $1 / 1$ complex can be made only for concentrations up to $0.066 \mathrm{M}$. Above $0.066 \mathrm{M}$, the observed deviation from linearity obtained with HP $\beta C D$ could be attributed to the saturation in free and complexed rifampicin.

Stability constants $\mathrm{Ks}$ and complexation efficiencies calculated for 1:1 rifampicin-CD complexes in the $0-0.23 \mathrm{M}$ RAMEB concentration range and in $0-0.066 \mathrm{M} \mathrm{HP} \beta \mathrm{CD}$ concentration range are inserted in Figure 3. Ks and CE values were close, suggesting the same type of interactions between the two CDs and rifampicin, i.e. an interaction limited to the internal cavity without involvement of methyl or hydroxypropyl pending groups. 
In order to aerosolize the rifampicin complex solutions into the lungs, their $\mathrm{pH}(\mathrm{pH} 9)$ need to be lowered to physiological $\mathrm{pH}$ (7.4). As this may result in complex destabilization and rifampicin precipitation, the physical stability of complexes was assessed after $1 / 6^{\text {th }}$ dilution in Ringer-HEPES medium pH 7.4 (Table 1). After one hour in Ringer-HEPES pH 7.4, no loss of rifampicin due to precipitation was observed. After 2 days in $\mathrm{pH} 7.4,97.9 \%$ of rifampicin remained solubilized. Hence, rifampicin-CD complexes can be formulated at $\mathrm{pH} 9$ for the best complexation efficiency and then extemporaneously buffered at $\mathrm{pH} 7.4$ for their nebulisation in the lung. Further studies performed after dilution in citrate buffer $\mathrm{pH} 4$ showed a rifampicin loss less than $5 \%$ after 1 hour and of $19.5 \%$ after 1 day. Rifampicin loss was attributed to rifampicin precipitation from supersaturated solutions. Supersaturation resulted from the dissociation of complexes induced by dilution and from a $\mathrm{pH}$-related decrease in rifampicin solubility. Higher rifampicin loss observed at $\mathrm{pH} 4$ compared to $\mathrm{pH} 7.4$ could be attributed to the inability of $\mathrm{CD}$ to complex rifampicin at this $\mathrm{pH}$ as observed in Fig. 2A, due to the protonation of piperazin group of $100 \%$ rifampicin molecules.

Formation of complexes between rifampicin and cyclodextrin resulted in an increase in rifampicin apparent solubility. This increase was linear with all tested RAMEB concentrations and, for a RAMEB concentration of $0.23 \mathrm{M}$, was equal to 22 times the rifampicin solubility determined at $\mathrm{pH} 7.4(2.9 \mathrm{mM})$. With $0.066 \mathrm{M}$ of $\mathrm{HP} \beta C \mathrm{C}$ the increase in rifampicin apparent solubility is equal to 7.6 times the rifampicin solubility determined at $\mathrm{pH} 7.4$. The increase of rifampicin apparent solubility by $\mathrm{CD}$ inclusion allows for an increase in the maximal dose nebulizable in the lungs. For example, in rats, usual volumes that are nebulised into lungs range from 10 to $400 \mu \mathrm{L}$ [25]. Therefore at $\mathrm{pH} 7.4$, based on rifampicin solubility, the maximal amount of rifampicin that can be administered into lungs is $0.96 \mathrm{mg}$. In contrast, by increasing rifampicin apparent solubility with $0.066 \mathrm{M}$ of $\mathrm{HP} \beta \mathrm{CD}$ or $0.23 \mathrm{M}$ of RAMEB, this amount would reach $7.5 \mathrm{mg}$ or $20.8 \mathrm{mg}$ respectively. In the purpose to administer rifampicin 
complex as a dry aerosol (e.g. obtained after freeze drying of the solution), the CE values allow to calculate the maximal amount of rifampicin per dosing. The $\mathrm{CE}$ values calculated for the two types of complexes formed with rifampicin are about 0.35 (Fig. 3), meaning that on average, about one out of four cyclodextrin molecules in solution forms a complex with one rifampicin molecule. The maximum amount of solid that can be administered in rat lungs is around $10 \mathrm{mg}$ [25]. Therefore, the amounts of rifampicin contained in $10 \mathrm{mg}$ of powder would be $1.36 \mathrm{mg}$ and $1.20 \mathrm{mg}$, for RAMEB and HPßCD complexes respectively, which is lower than with the complexes in solution. Furthermore, this amount of rifampicin is low in comparison to the aerosolization of $10 \mathrm{mg}$ of pure rifampicin. However, due to higher solubility of the complex than free rifampicin, the solubilisation rate should be faster with the complex. As a consequence, the maximal rifampicin concentration reachable in the ELF could be higher when rifampicin will be administered as CD complex than pure. 


\section{Transport across an epithelial cell barrier model}

The goal of our study was to increase rifampicin concentration in ELF. This concentration is a balanced value depending on the amount of rifampicin administered into the lung and its rate of elimination. The passive diffusion of molecules from the lung lumen to the blood is mainly limited by the lung epithelium, due to the presence of tight junctions between type I pneumocytes. In order to evaluate the effect of rifampicin complexation with $\mathrm{CD}$ upon its diffusion, we studied the rifampicin linear flux, as defined by Fick's law, under free and complexed form across a Calu-3 cell layer, an epithelial alveolar model forming high level of tight junction [19].

HP $\beta C D$ and especially RAMEB are known to potentially reduce cell membrane viscosity due to cholesterol extraction, resulting in an increase in membrane permeability and cell toxicity [26]. Therefore, to assess the effects of CD on epithelial cells, the permeability of fluorescein and rifampicin was determined in the absence or in the presence of $0.066 \mathrm{M}$ of free $\mathrm{HP} \beta \mathrm{CD}$ or $0.076 \mathrm{M}$ of free RAMEB (Figure 4). Fluorescein permeability was not increased by the presence of CDs. This demonstrated that CDs at these concentrations did not alter the paracellular transport and that tight junction integrity was maintained, suggesting the absence of toxicity for the cell monolayer in the timescale of 1 hour. A recent toxicity study performed by incubating Calu-3 cells with various CDs for a longer periods of 4 hours showed that at a $0.050 \mathrm{M}$ concentration HP $\beta$ CD caused no LDH leakage from Calu-3 cell and minor reduction of the number of viable cells, while RAMEB induced cell death and membrane damage [27]. In our studies, rifampicin permeability measured in the presence of $\mathrm{HP} \beta C D$ or RAMEB was slightly lower (1.4 times) than with rifampicin alone, indicating that after 1 hour incubation CDs did not increase rifampicin transcellular transport due to interactions with the epithelial cell membrane. The slightly lower permeability measured in presence of CDs was attributed 
to a complexation of the free rifampicin with CDs in the Ringer-HEPES medium, even though the ability of rifampicin to be complexed with $\mathrm{CD}$ was weak at $\mathrm{pH}$ 7.4.

As the presence of CDs did not modify the integrity of the cell monolayer in the timescale of 1 hour, rifampicin transport across the alveolar epithelial cell model was performed (Fig. 5). For all experiments, rifampicin fluxes were proportional to the total rifampicin concentration. This suggests that at least in the rifampicin concentration ranges studied, in the presence or absence of $\mathrm{CD}$, transport of rifampicin across the cell layer was a diffusion-driven process, excluding the involvement of membrane transporter [28]. As shown by the slopes of the curve in Figure 5, for a given total concentration of rifampicin, flux values were lower with rifampicin complex than with rifampicin alone. Results also showed that rifampicin flux measured in presence of complex was independent of the nature of CDs.

Considering free rifampicin, permeability value $\left(1.69 \pm 0.40 \times 10^{-6} \mathrm{~cm} / \mathrm{s}\right)$ calculated from the slope of the linear regression of the rifampicin flux versus concentration curve (Fig.5), was close to values generally reported in literature across rat jejunum or ileum $[28,29]$, or across Caco-2 cell monolayer model [30] $\left(2 \times 10^{-6} \mathrm{~cm} / \mathrm{s}\right)$. This value is lower than values observed on everted rat gut sac model for low permeable drugs listed by the US FDA (furosemide, ranitidine) [29]. This suggests that rifampicin is a drug with low lung permeability and hence qualifies to be used for lung-targeted aerosol therapy.

As shown on Figure 5, the highest flux value found with free rifampicin alone was $5 \times 10^{-12}$ $\mathrm{mol} / \mathrm{cm}^{2} / \mathrm{s}$ and was observed when rifampicin reached saturation concentration, i.e. $2.6 \mathrm{mM}$. When rifampicin was complexed with RAMEB, this flux value was reached for a much higher total rifampicin concentration $(21.6 \mathrm{mM})$. Due to their large $\mathrm{Mw}$ and their polar character, CDs and CD complexes are indeed generally considered as not being able to diffuse across cell layers. As a matter of fact, CD permeability values recently measured across Calu3 cell layers were close to $6.7 \times 10^{-8} \mathrm{~cm} / \mathrm{s}$ [27], which is 25 times lower than the rifampicin 
permeability value determined in the present study $\left(1.69 \pm 0.40 \times 10^{-6} \mathrm{~cm} / \mathrm{s}\right)$. Hence, the flux of the rifampicin was only related to free molecules fraction, and for a given total rifampicin concentration, rifampicin fluxes in the presence of $\mathrm{CD}$ complex were lower than in the absence of $\mathrm{CD}$. The linear increase in flux values as a function of the total rifampicin concentration was attributed to the proportional increase in free rifampicin concentration. As for both complexes Ks values were close, rifampicin fluxes measured with both RAMEB or $\mathrm{HP} \beta C D$ were similar for a given total rifampicin concentration. For the highest total rifampicin concentration tested on the cells, i.e. $21.6 \mathrm{mM}$ with RAMEB complexes, [obtained with a $1 / 3^{\text {rd }}$ dilution of the highest point observed in the phase diagram (Fig. 3)], the rifampicin flux was similar to the one measured with free rifampicin at saturation concentration $(2.6 \mathrm{mM})$, suggesting that free rifampicin was close to saturation. Therefore, increase in apparent rifampicin concentrations over $21.6 \mathrm{mM}$ would not in theory result in higher rifampicin fluxes through the cell layers. From a formulation viewpoint, this means that solutions of rifampicin complex at or above a $21.6 \mathrm{mM}$ rifampicin total concentration should maintain saturation of rifampicin in the epithelial lining fluid and should act as a sustained release system. 


\section{Antibacterial activity}

In the objective to evaluate the bacteriostatic activity of rifampicin complex, we measured the MIC values against A. baumannii CIP7010T. Value observed for rifampicin alone was comprised in the interval $] 10 ; 20\left[\mu \mathrm{g} / \mathrm{mL}\left(12 \times 10^{-3}-24 \times 10^{-3} \mathrm{mM}\right)\right.$. When rifampicin was present under HP $\beta C D$ or RAMEB complexes, MIC values were between $] 3.75 ; 7.5[\mu \mathrm{g} / \mathrm{mL}$ $\left(4.6 \times 10^{-3}-9.1 \times 10^{-3} \mathrm{mM}\right)$ and $] 17.5 ; 35\left[\mu \mathrm{g} / \mathrm{mL}\left(21 \times 10^{-3}-42 \times 10^{-3} \mathrm{mM}\right)\right.$ respectively. Hence, rifampicin-CD solutions had bacteriostatic activities against A. baumannii CIP7010T equivalent to (RAMEB) or higher than (HP $\beta C D)$ a solution of rifampicin alone, suggesting that the complexation process does not alter the rifampicin bacteriostatic activity. Similar results were found on in vitro anti-tubercular activity of rifampicin by Rao et al. [23]. Complexation of rifampicin with $\beta$-CD or hydroxyl-ethyl- $\beta$-cyclodextrin reduced MIC values to half. Furthermore, considering that a fraction rifampicin was complexed with $\mathrm{CD}$ and that only the free fraction of rifampicin should be active, RAMEB and HP $\beta C D$ should improve rifampicin activity. 


\section{Conclusion}

In the aim to improve treatment efficiency against pulmonary infections and avoid the apparition of MDR gram negative bacteria, a new rifampicin - cyclodextrin formulation was developed for rifampicin administration by nebulization. The targeting of lung by direct administration of rifampicin by nebulization should be well adapted since its permeability across cell monolayer is low. Formulation parameters such as $\mathrm{pH}$ and cyclodextrin type were optimized to increase the complexation efficiency and rifampicin apparent solubility. Complexes formed with RAMEB or HP $\beta C D$ maintained similar or higher bacteriostatic activity against A. Baumannii. Furthermore, the use of $\mathrm{CD}$ allows increase in the administrable dose and did not increase rifampicin lung absorption. This would allow maintaining high rifampicin concentration in the ELF which is a benefit since rifampicin pharmacodynamic is concentration dependant. Further bacteriological and in vivo pharmacokinetic studies are envisaged to evaluate this new formulation. 


\section{Acknowledgements}

Calu-3 cells were kindly given by Prof. Frédéric Becq, UMR CNRS 6187, University f

Poitiers. The authors are grateful to Mrs. Manuella Marliat for her technical assistance in performing bacteriological testing. 


\section{References}

[1] A. Montero, X. Corbella, J. Ariza, Clinical relevance of Acinetobacter baumannii ventilator-associated pneumonia. Critical Care Medicine 31(10) (2003) 2557-2559.

[2] G. Da Silva, L. Dijkshoorn, T. van der Reijden, B. van Strijen, A. Duarte, Identification of widespread, closely related Acinetobacter baumannii isolates in Portugal as a subgroup of European clone II. Clinical Microbiology and Infection 13(2) (2007) 190-195.

[3] L.C. Kuo, C.C. Lai, C.H. Liao, C.K. Hsu, Y.L. Chang, C.Y. Chang, P.R. Hsueh, Multidrug-resistant Acinetobacter baumannii bacteraemia: clinical features, antimicrobial therapy and outcome. Clinical Microbiology and Infection 13(2) (2007) 196-198.

[4] M. Saballs, M. Pujol, F. Tubau, C. Pena, A. Montero, M.A. Dominguez, F. Gudiol, J. Ariza, Rifampicin/imipenem combination in the treatment of carbapenemresistant Acinetobacter baumannii infections. J. Antimicrob. Chemother. 58(3) (2006) 697-700.

[5] M.M. Wroblewska, K.J. Towner, H. Marchel, M. Luczak, Emergence and spread of carbapenem-resistant strains of Acinetobacter baumannii in a tertiary-care hospital in Poland. Clinical Microbiology and Infection 13(5) (2007) 490-496.

[6] P. Bogaerts, T. Naas, I. Wybo, C. Bauraing, O. Soetens, D. Pierard, P. Nordmann, Y. Glupczynski, Outbreak of Infection by Carbapenem-Resistant Acinetobacter baumannii Producing the Carbapenemase OXA-58 in Belgium. J. Clin. Microbiol. 44(11) (2006) 4189-4192.

[7] J.M. Coelho, J.F. Turton, M.E. Kaufmann, J. Glover, N. Woodford, M. Warner, M.-F. Palepou, R. Pike, T.L. Pitt, B.C. Patel, D.M. Livermore, Occurrence of Carbapenem-Resistant Acinetobacter baumannii Clones at Multiple Hospitals in London and Southeast England. J. Clin. Microbiol. 44(10) (2006) 3623-3627. 
[8] A. Bertini, A. Giordano, P. Varesi, L. Villa, C. Mancini, A. Carattoli, First Report of the Carbapenem-Hydrolyzing Oxacillinase OXA-58 in Acinetobacter baumannii Isolates in Italy. Antimicrob. Agents Chemother. 50(6) (2006) 2268-2269.

[9] V. Trottier, N. Namias, D.G. Pust, Z. Nuwayhid, R. Manning, A.C. Marttos Jr, M.B. Dunham, C.I. Schulman, M.G. McKenney, Outcomes of Acinetobacter baumannii infection in critically ill surgical patients. Surgical Infections 8(4) (2007) 437-443.

[10] K.P. Holloway, N.G. Rouphael, J.B. Wells, M.D. King, H.M. Blumberg, Polymyxin B and Doxycycline Use in Patients with Multidrug-Resistant Acinetobacter baumannii Infections in the Intensive Care Unit. Ann Pharmacother 40(11) (2006) 19391945.

[11] H. Kallel, M. Bahloul, L. Hergafi, M. Akrout, W. Ketata, H. Chelly, C.B. Hamida, N. Rekik, A. Hammami, M. Bouaziz, Colistin as a salvage therapy for nosocomial infections caused by multidrug-resistant bacteria in the ICU. International Journal of Antimicrobial Agents 28(4) (2006) 366-369.

[12] J. Li, C.R. Rayner, R.L. Nation, R.J. Owen, D. Spelman, K.E. Tan, L. Liolios, Heteroresistance to Colistin in Multidrug-Resistant Acinetobacter baumannii. Antimicrob. Agents Chemother. 50(9) (2006) 2946-2950.

[13] M.J. Rodriguez-Hernandez, J. Saugar, F. Docobo-Perez, B.G. de la Torre, M.E. Pachon-Ibanez, A. Garcia-Curiel, F. Fernandez-Cuenca, D. Andreu, L. Rivas, J. Pachon, Studies on the antimicrobial activity of cecropin A-melittin hybrid peptides in colistin-resistant clinical isolates of Acinetobacter baumannii. Journal of Antimicrobial Chemotherapy 58(1) (2006) 95-100.

[14] T. Gumbo, A. Louie, M.R. Deziel, W. Liu, L.M. Parsons, M. Salfinger, G.L. Drusano, Concentration-dependent Mycobacterium tuberculosis killing and prevention of resistance by rifampin. Antimicrob. Agents Chemother. (2007) AAC.01533-01506.

[15] S.Q. Henwood, W. Liebenberg, L.R. Tiedt, ouml, A.P. tter, M.M. de Villiers, Characterization of the Solubility and Dissolution Properties of Several New Rifampicin Polymorphs, Solvates, and Hydrates. Drug Development and Industrial Pharmacy 27(10) (2001) 1017 - 1030. 
[16] S. Agrawal, R. Panchagnula, Dissolution test as a surrogate for quality evaluation of rifampicin containing fixed dose combination formulations. International Journal of Pharmaceutics 287(1-2) (2004) 97-112.

[17] M.D. Louey, L. Garcia-Contreras, Controlled release products for respiratory delivery. American Pharmaceutical Review 7(4) (2004) 82-87.

[18] B. Evrard, P. Bertholet, M. Gueders, M.P. Flament, G. Piel, L. Delattre, A. Gayot, P. Leterme, J.M. Foidart, D. Cataldo, Cyclodextrins as a potential carrier in drug nebulization. Journal of Controlled Release 96(3) (2004) 403-410.

[19] B. Forbes, C. Ehrhardt, Human respiratory epithelial cell culture for drug delivery applications. European Journal of Pharmaceutics and Biopharmaceutics 60(2) (2005) 193-205.

[20] T. Loftsson, D. Hreinsdottir, M. Masson, Evaluation of cyclodextrin solubilization of drugs. International Journal of Pharmaceutics 302(1-2) (2005) 18-28.

[21] S. Lundquist, M. Renftel, J. Brillault, L. Fenart, R. Cecchelli, M.P. Dehouck, Prediction of drug transport through the blood-brain barrier in Vivo: A comparison between two in Vitro cell models. Pharmaceutical Research 19(7) (2002) 976-981.

[22] The Merck Index, 11th Edn, Monograph 8215 (1989) 1308.

[23] B.P. Rao, S. Suresh, C. Narendra, Balasangameshwer, Physicochemical characterization of $\beta$-cyclodextrin and hydroxy ethyl $\beta$-cyclodextrin complexes of rifampicin. Ars Pharmaceutica 47(1) (2006) 37-59.

[24] M.E. Brewster, T. Loftsson, Cyclodextrins as pharmaceutical solubilizers. Advanced Drug Delivery Reviews 59(7) (2007) 645-666.

[25] M. Sakagami, In vivo, in vitro and ex vivo models to assess pulmonary absorption and disposition of inhaled therapeutics for systemic delivery. Advanced Drug Delivery Reviews 58(9-10) (2006) 1030-1060.

[26] A. Tsamaloukas, H. Szadkowska, P.J. Slotte, H. Heerklotz, Interactions of Cholesterol with Lipid Membranes and Cyclodextrin Characterized by Calorimetry. Biophys. J. 89(2) (2005) 1109-1119. 
[27] L. Matilainen, T. Toropainen, H. Vihola, J. Hirvonen, T. Jarvinen, P. Jarho, K. Jarvinen, In vitro toxicity and permeation of cyclodextrins in Calu-3 cells. Journal of Controlled Release doi: 10.1016/j (2007).

[28] T.T. Mariappan, S. Singh, Evidence of Efflux-Mediated and Saturable Absorption of Rifampicin in Rat Intestine Using the Ligated Loop and Everted Gut Sac Techniques. Mol. Pharmaceutics 1(5) (2004) 363-367.

[29] T.T. Mariappan, S. Singh, Positioning of Rifampicin in the Biopharmaceutics Classification System (BCS). Clinical Research and Regulatory Affairs 23(1) (2006) 1 10.

[30] E.C.Y. Chan, W.L. Tan, P.C. Ho, L.J. Fang, Modeling Caco-2 permeability of drugs using immobilized artificial membrane chromatography and physicochemical descriptors. Journal of Chromatography A 1072(2) (2005) 159-168. 


\section{Figure legends}

Figure 1: Rifampicin chemical structure

Figure 2: A) Variation of apparent rifampicin solubility versus $\mathrm{pH}$ in absence and presence of $5 \%(\mathrm{~m} / \mathrm{v})$ of HP $\beta$ CD or RAMEB. Suspensions were stirred during 7 days at $37^{\circ} \mathrm{C}$, and then filtered on $0.2 \mu \mathrm{m}$ filters. Buffers used: pH 4 (0.05 M citrate-phosphate buffer), pH 7.4 (0.05M PBS) and pH 9 (0.05 M borate buffer). Data are means \pm SD of 3 samples. B) Variation of rifampicin ionic state versus $\mathrm{pH}$, calculated using HendersonHasselbach equation and considering only the pKa of 1.7 and 7.9.

Figure 3: Phase solubility diagrams of rifampicin in the presence of HP $\beta C D$ or of RAMEB. Conditions: $\mathbf{p H}=9$; temperature: $37^{\circ} \mathrm{C}$; stirring time: 7 days; samples were filtered on $0.2 \mu \mathrm{m}$ filters. Data are means \pm SD of 3 samples. Dotted line corresponds to linear regression performed with values obtained with RAMEB. Solid line corresponds to linear regression performed with values obtained with $H P \beta C D$ in the range $0-0.066$ M.

Figure 4: Rifampicin permeability measured for an initial rifampicin concentration of $0.34 \mathrm{mM}$ in the presence of $0.066 \mathrm{M}$ of free HP $\beta C D$ or $0.076 \mathrm{M}$ of free RAMEB. Incubation time of one hour in Ringer - HEPES buffered at $\mathbf{p H}=7.4,37^{\circ} \mathrm{C}$. Data are mean \pm SD of 3 samples.

Figure 5: Rifampicin transport study across Calu-3 cell monolayer. Grey solid line: rifampicin flux measured without CD. Dotted line: Rifampicin flux measured in the presence of RAMEB. Solid line: Rifampicin flux measured in presence of HP $\beta C D$. Cells were incubated at $37^{\circ} \mathrm{C}$ in Ringer-HEPES pH $=7.4$. Fluxes were measured in initial conditions, i.e. $C_{a} \leq 5 \%$ of $C_{d}$ (for experimental details see materials and methods). Data are means \pm SD of 3 samples 


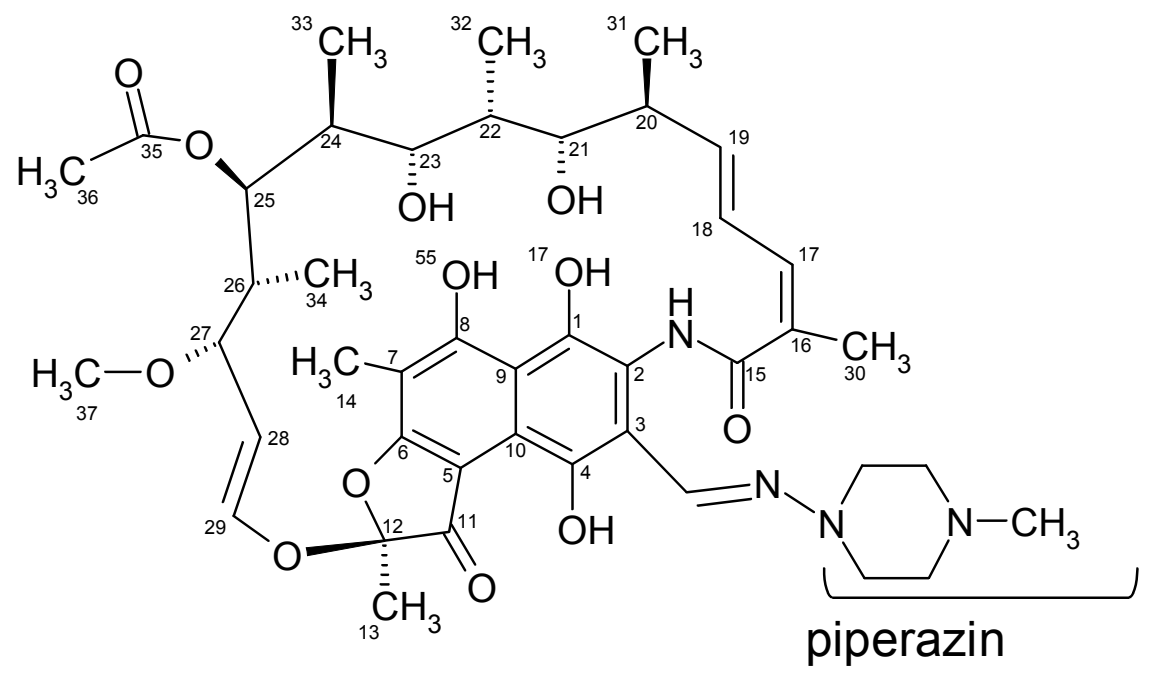

Figure 1 
Figure(s)
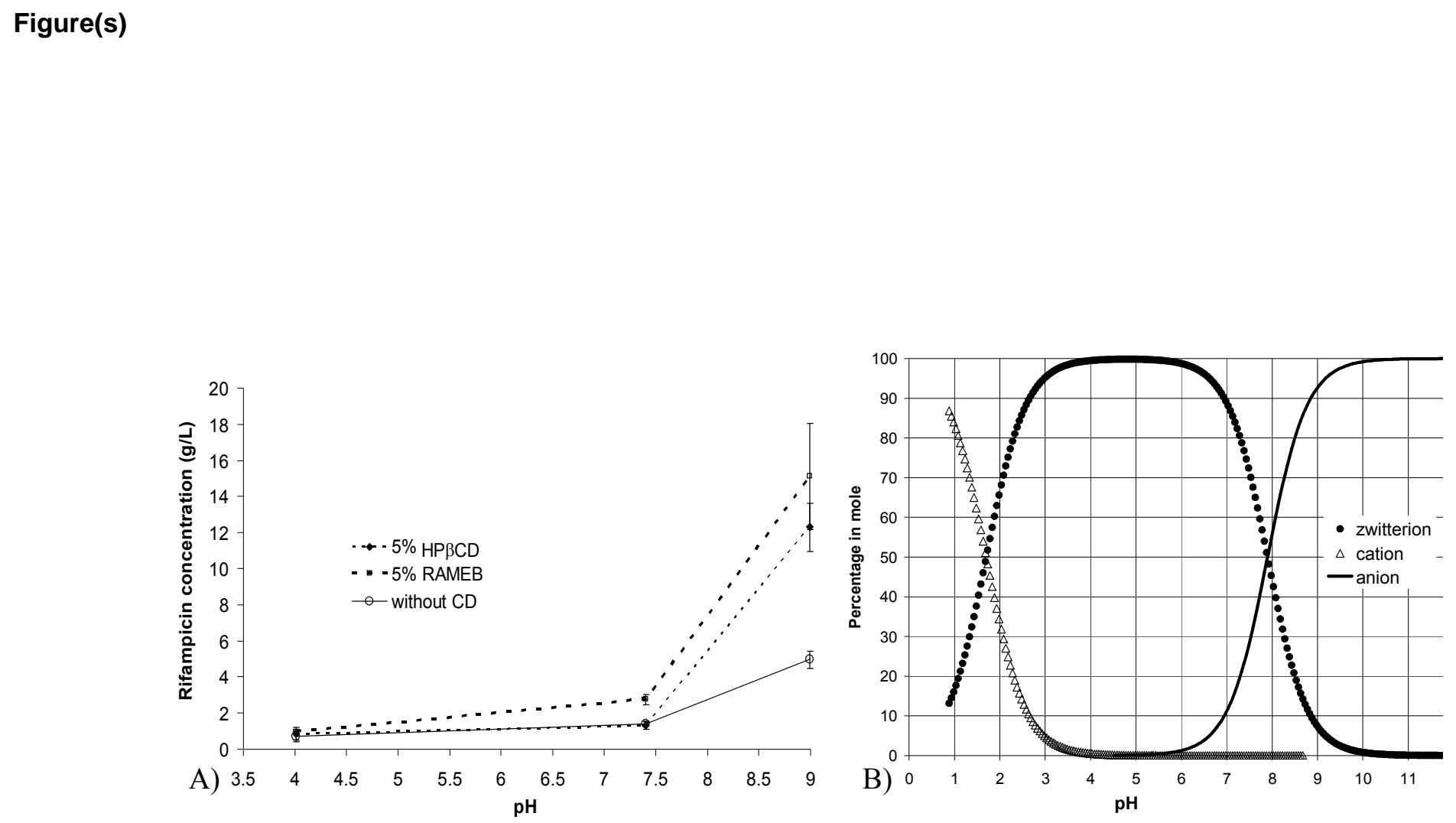

\section{Figure 2}




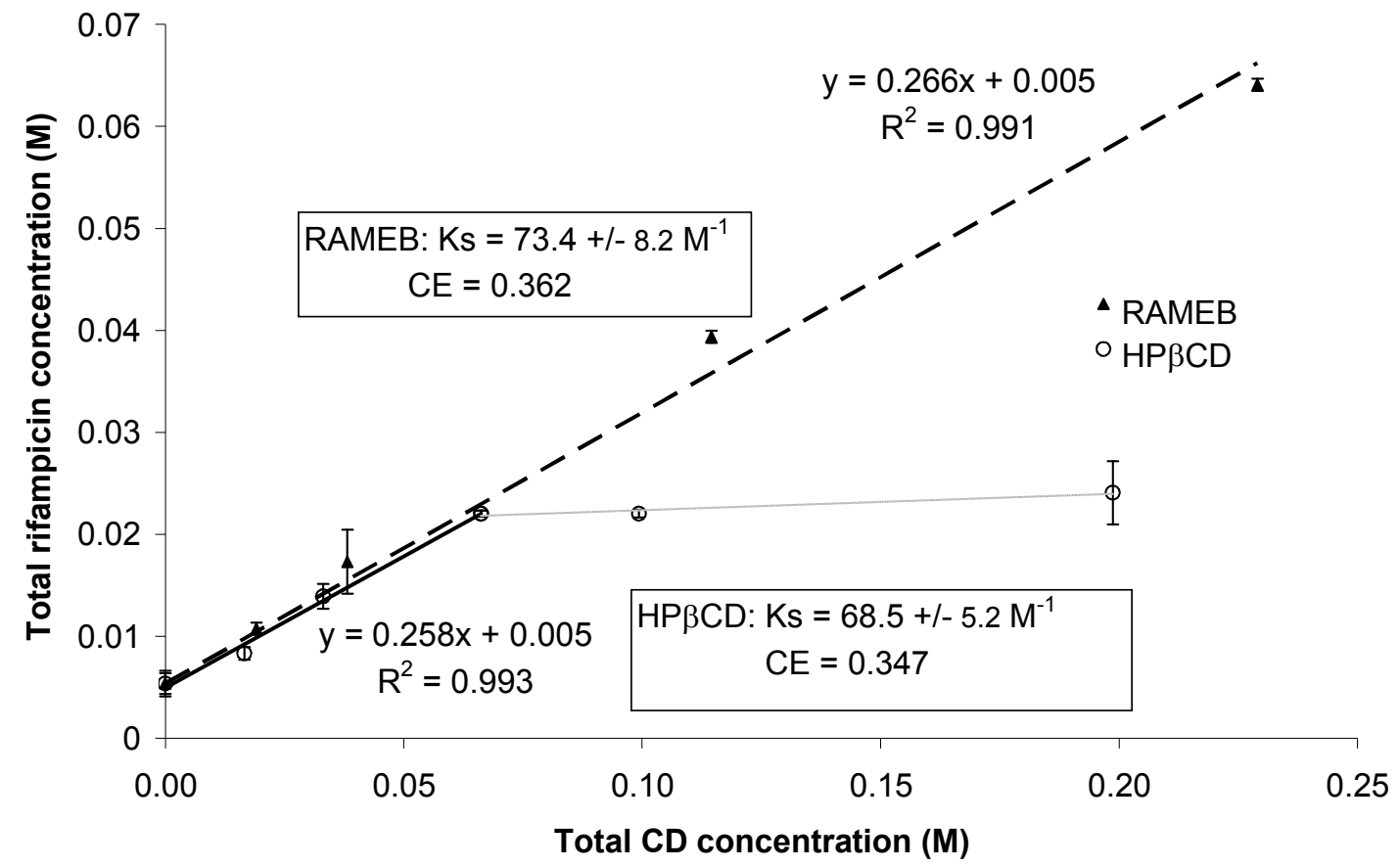

Figure 3 


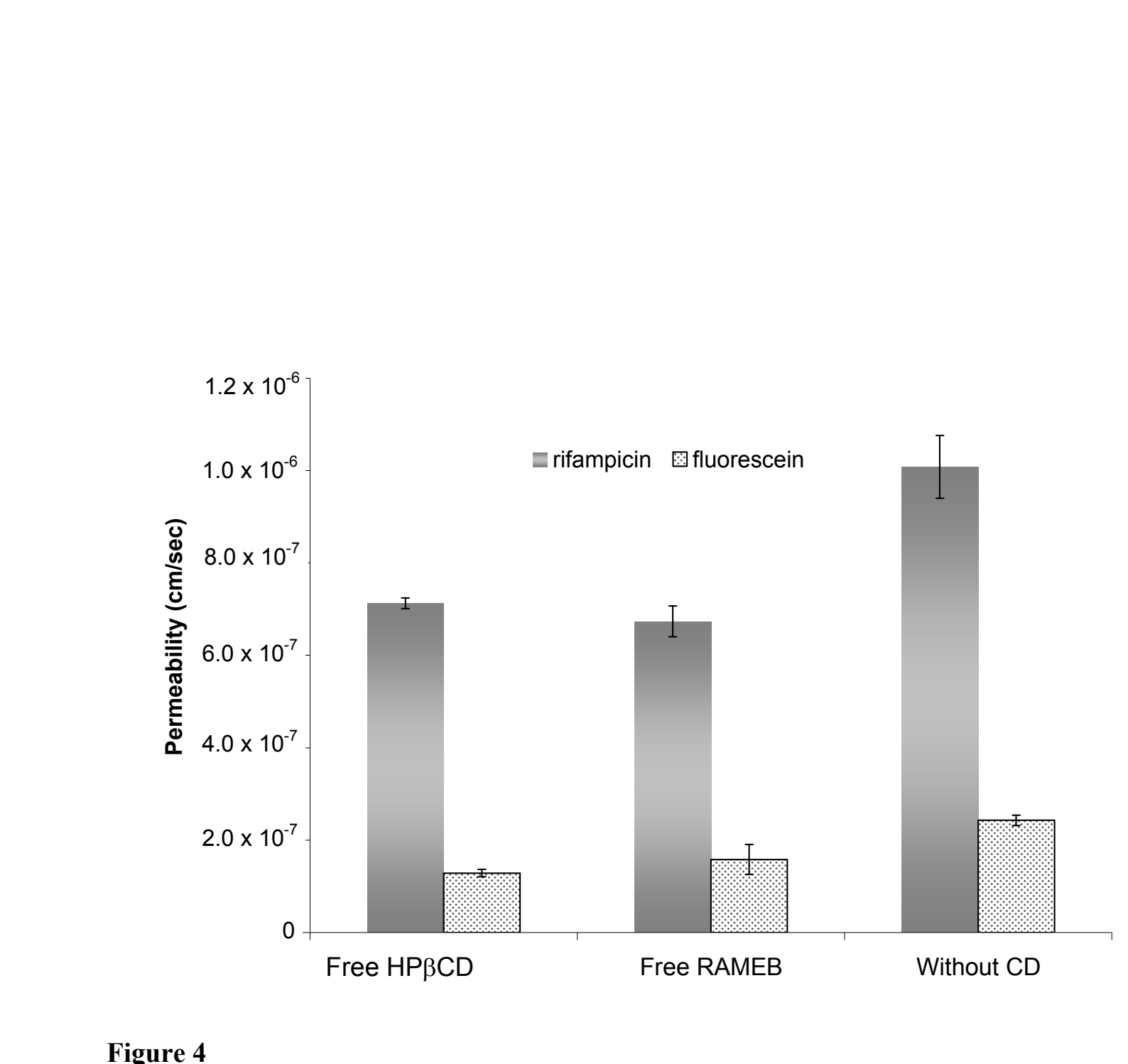

Figure 4

Figure(s)

Free HPBCD Free RAMEB Without CD

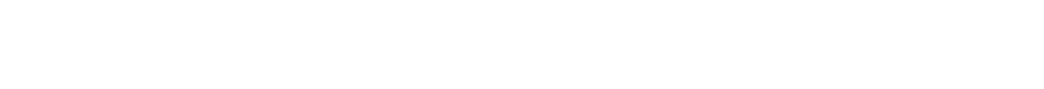

(1)

(1)

(

(

\section{Figure(s)}

\section{(2)}




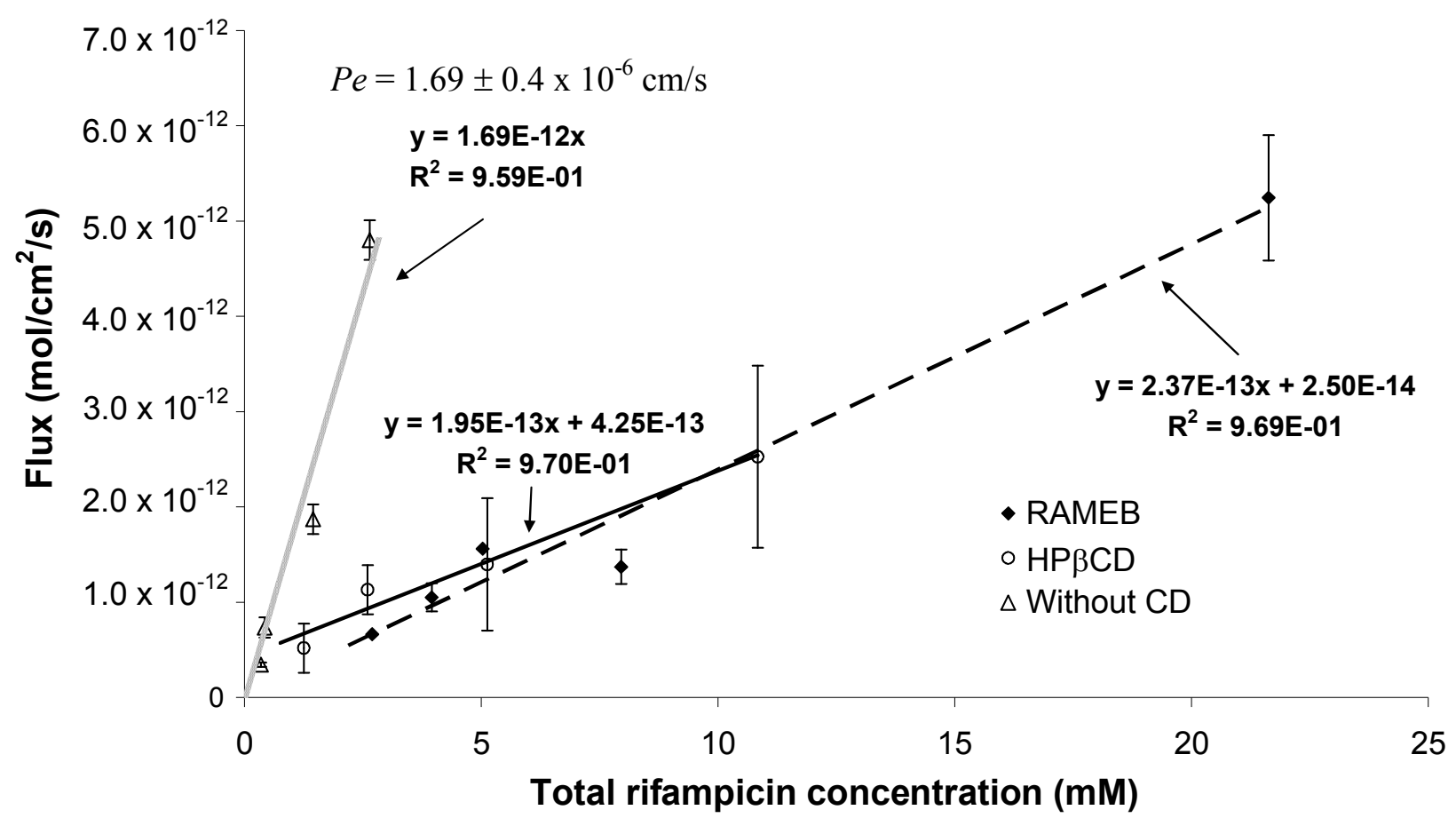

Figure 5 
Table 1: Percentage of the rifampicin remained after diluting 6 times the RAMEB (0.23 M) - rifampicin solution (59 mM ) in Ringer-HEPES medium (pH 7.4) or in $0.1 \mathrm{M}$ of citric acid /citrate buffer (pH 4). Samples were stirred at room temperature. Solutions were filtered on $0.2 \mu \mathrm{m}$ filter before rifampicin assay.

\begin{tabular}{|c|c|c|}
\hline & One hour & 2 days \\
\hline $\mathrm{pH} 9 \rightarrow \mathrm{pH} \mathrm{4}$ & $96.7 \%$ & $80.5 \%$ \\
\hline $\mathrm{pH} 9 \rightarrow \mathrm{pH} 7.4$ & $100 \%$ & $97.9 \%$ \\
\hline
\end{tabular}

